Rochester Institute of Technology

RIT Scholar Works

Summer 7-12-2020

\title{
Motivational Principles and Personalisation Needs for Geo- Crowdsourced Intangible Cultural Heritage Mobile Applications
}

\author{
Federica Lucia Vinella \\ Utrecht University \\ Ioanna Lykourentzou \\ Utrecht University \\ Konstantinos Papangelis \\ Rochester Institute of Technology
}

Follow this and additional works at: https://scholarworks.rit.edu/other

Part of the Other Computer Sciences Commons

\section{Recommended Citation}

Federica Lucia Vinella, loanna Lykourentzou, and Konstantinos Papangelis. 2020. Motivational Principles and Personalisation Needs for GeoCrowdsourced Intangible Cultural Heritage Mobile Applications. In Adjunct Proceedings of the 28th ACM Conference on User Modeling, Adaptation and Personalization (UMAP '20 Adjunct), July 14-17, 2020, Genoa, Italy. ACM, New York, NY, USA, 8 pages. https://doi.org/ $10.1145 / 3386392.3399284$

This Conference Proceeding is brought to you for free and open access by the Faculty \& Staff Scholarship at RIT Scholar Works. It has been accepted for inclusion in Presentations and other scholarship by an authorized administrator of RIT Scholar Works. For more information, please contact ritscholarworks@rit.edu. 


\section{Motivational Principles and Personalisation Needs for Geo-Crowdsourced Intangible Cultural Heritage Mobile Applications Author's copy - DOI: 10.1145/3386392.3399284}

\author{
Federica Lucia Vinella \\ f.l.vinella@uu.nl \\ Department of Information and \\ Computing Sciences \\ Utrecht, the Netherlands
}

\author{
Ioanna Lykourentzou \\ i.lykourentzou@uu.nl \\ Department of Information and \\ Computing Sciences \\ Utrecht, the Netherlands
}

\author{
Konstantinos Papangelis \\ kxpigm@rit.edu \\ School of Interactive Games and \\ Media, Golisano College of \\ Computing and Information Sciences \\ Rochester, NY
}

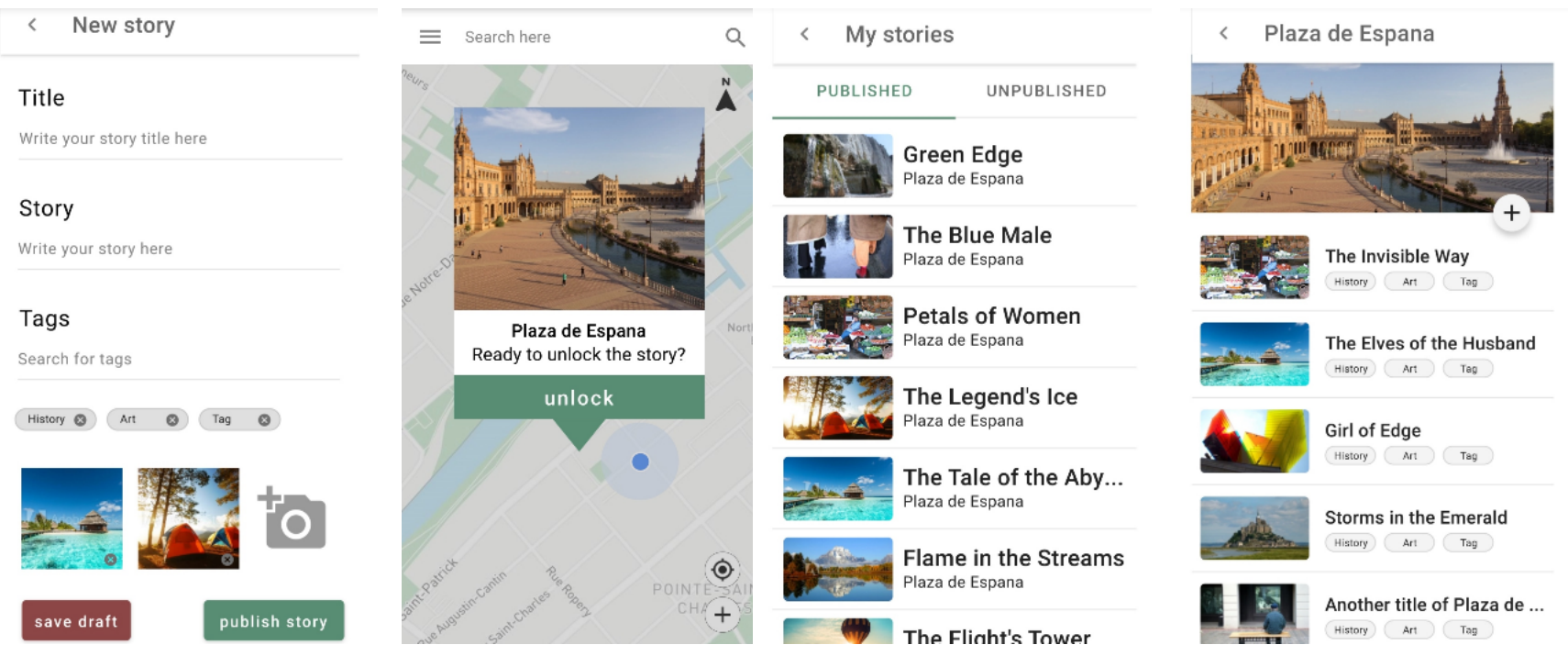

Figure 1: The StoryBee application has been designed according to four key literature recommendations for mobileICH: imaging, geo-referencing, contextualization and sharing.

\begin{abstract}
Whether it's for altruistic reasons, personal gains or third party's interests, users are influenced by different kinds of motivations when making use of mobile geo-crowdsourcing applications (geoCAs). These reasons, extrinsic and/or intrinsic, must be factored in when evaluating the use intention of these applications and how effective they are. A functional geoCA, particularly if designed for Volunteered Geographic Information (VGI), is the one that persuades and engages its users, by accounting for their diversity of needs across a period of time. This paper explores a number of proven and novel

Permission to make digital or hard copies of all or part of this work for personal or classroom use is granted without fee provided that copies are not made or distributed for profit or commercial advantage and that copies bear this notice and the full citation on the first page. Copyrights for components of this work owned by others than ACM must be honored. Abstracting with credit is permitted. To copy otherwise, or republish, to post on servers or to redistribute to lists, requires prior specific permission and/or a fee. Request permissions from permissions@acm.org.

UMAP '20 Adjunct, fuly 14-17, 2020, Genoa, Italy

(c) 2020 Association for Computing Machinery.

ACM ISBN 978-x-xxxx-xxxx-x/YY/MM...\$15.00

https://doi.org/10.1145/nnnnnnn.nnnnnnn
\end{abstract}

motivational factors destined for the preservation and collection of Intangible Cultural Heritage (ICH) through geoCAs. By providing an overview of personalisation research and digital behaviour interventions for geo-crowdsoured $\mathrm{ICH}$, the paper examines the most relevant usability and trigger factors for different crowd users, supported by a range of technology-based principles. In addition, we present the case of StoryBee, a mobile geoCA designed for "crafting stories" by collecting and sharing users' generated content based on their location and favourite places. We conclude with an openended discussion about the ongoing challenges and opportunities arising from the deployment of geoCAs for $\mathrm{ICH}$.

\section{CCS CONCEPTS}

- Human-centered computing $\rightarrow$ Collaborative and social computing; Computer supported cooperative work; Collaborative content creation; Ubiquitous and mobile computing; - Social and professional topics $\rightarrow$ Computing and business. 


\section{KEYWORDS}

intangible cultural heritage; sustainability; mobile crowdsourcing

ACM Reference Format:

Federica Lucia Vinella, Ioanna Lykourentzou, and Konstantinos Papangelis. 2020. Motivational Principles and Personalisation Needs for GeoCrowdsourced Intangible Cultural Heritage Mobile Applications Author's copy - DOI: 10.1145/3386392.3399284. In Adjunct Proceedings of the 28th ACM Conference on User Modeling, Adaptation and Personalization (UMAP '20 Adjunct), fuly 14-17, 2020, Genoa, Italy. ACM, New York, NY, USA, 8 pages. https://doi.org/10.1145/nnnnnnn.nnnnnnn

\section{INTRODUCTION}

Within the field of Cultural Heritage $(\mathrm{CH})$, the many intangible objects that form part of a city's cultural richness compose what is known as urban Intangible Cultural Heritage (ICH) [35]. Recently, an increased interest has risen for the use of crowdsourcing to gather geographical ICH data through the participation of citizens who can upload, share and recommend content. Volunteer Generated Information (VGI) ICH applications possess three distinguishing elements, namely diverse crowds, diverse locations and an extensive heterogeneity of the dataset, which model these systems as complex real-world applications. The ubiquitous nature of mobile technology [21], for example in the form of smartphones, makes designing mobile applications that capture and document novel and old information based on places of interest, a rather attractive solution $[22,26]$. Engaging users, both in producing and in benefiting of the content is something that Participatory Geographical Information Systems (PGIS) have been good at [16]. The same PGIS that are used for a number of humanitarian scopes, such as supporting communities in times of emergency (e.g. crisis and community maps [17]), are also popular options when looking for open source data, that is, for instance, the free editable map of the world by OpenStreetMap (OSM). This example of PGIS powers data mining resources to a large group of users and emphasizes local knowledge through the help of contributors using aerial imagery, GPS devices, and low-tech field maps. In accordance with the centrality of the users' participation in geoCAs for $\mathrm{ICH}$, we herein discuss different approaches to modelling optimal systems designed for the acquisition and retention of users by focusing on tailored motivational factors. In this paper we provide a comprehensive list of motivational factors that affect user motivation and retention in crowdsourcing ICH. We focus specifically on motivational features for location-based crowdsourcing ICH applications, then discuss one successful simulation of the kind [14] followed by several other examples of frameworks for smart cultural heritage. On account of the recommended guidelines, we discuss the recent development of the StoryBee geoCA, designed to collect and suggest stories which have been inspired by places of interest and have been written by users. We conclude the work with a short discussion dedicated to the opportunities and challenges ahead.

\section{BACKGROUND}

Documenting ICH in the 21st century is a pursuit often challenged by the expansion of cultural intermingling, a trend attributed to the effects of globalisation. With the prospect of the human race moving towards an even more changeable and uncertain future,

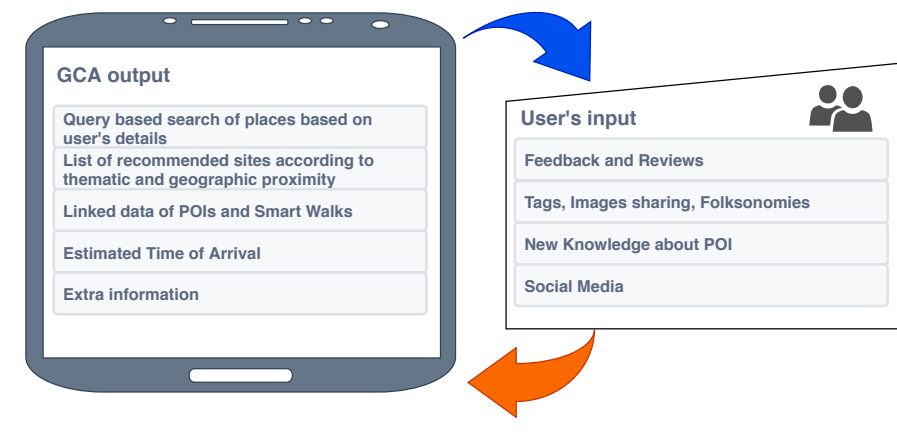

Figure 2: geoCA life cycle with user and context awareness features as explored by the work of [14]

collecting the intangible products of these checkpoints in time becomes a pivotal facet of the history of humanity [10]. A mobile application that can help capture the ICH of a place, could swiftly bridge the gaps between those cultures at risk of extinction and the appropriate cultural institutions, whilst placing the user at the center of the preservation process. Such an application can create a safe zone from where the act of understanding cultural diversity on the one hand, and the growth of personal sensitivity towards the heterogeneity of ICH on the other, can together develop into practices that are widely taken up and encouraged. A good example of an intangible mobile cultural heritage application is the one made for Castello, a neighborhood in Cagliari, Italy [14]. The goal of the app is to guide tourists around the neighbourhood, tell them which cultural heritage sites are worth visiting and if there is enough time to do so. This is done using a simple query based on the user's demographics, such as age and physical ability. The app presents the user a list of site recommendations to visit according to thematic and geographic proximity. These lists are connected to multiple Points Of Interest (POIs) and Smart Walks. These smart walks are routes to a given place with several things to see on the way there. The app calculates the time to get there and also places the POI on a smart walk, or route, with more POIs. Once a user has arrived at a POI, the app presents relevant content, made of some essential guidance and information obtained about it [15].

The user walks from a start point to a finish point, with several POIs on the way. This also allows for the intangible cultural heritage that is linked to the place to be disseminated [14]. After a visit, the user can rate each visited POI in terms of the quality of service offered. Users can also comment, tag, upload images, add folksonomies (i.e. taxonomies about a physical place used by the community) and new knowledge about the POI, which might be a landmark [14]. This way every time a POI is visited, more intangible information about it will become available for the next visitor. Another user can decide to take this or another route based on this information. All of this feedback can then be shared on social media, thus reaching more potential visitors. The main users of such system are not only the users (maybe end-users) but also the moderators. Moderators can improve the application by using feedback from general users, and these users can, in turn, enrich the information originally posted by the moderators [15]. This method 
ensures the broad participation and sharing of information between all actors and creates a balance between material cultural heritage and local wisdom [9]. Ad-hoc smart environments for the disclosure of cultural heritage should provide a set of functionalities for recommending personalised cultural experiences, alike the SNOPS platform developed by Amato et al. [2]. The SNOPS multi-layer architectural pattern follows the suggestions of Service Oriented Architecture (SOA), participatory sensing and IoT platforms for smart cities. It combines archaeological information of historical sites in the south of Italy with context data (observed paintings, current location, weather forecast, crowding at the entrance of the buildings, etc.), user preferences (both declared and acquired during the visit), opinions and behaviours of other people who have similar experiences [2]. Interestingly, the system is designed to encourage the crowd to participate in the shaping of the cultural knowledge in an intuitive and accessible fashion by providing features that ease the action of visiting heritage sites without exceeding in information overload, a risk associated with the detriment of usage of the application. Finally, the system provides all the necessary information such as costs, logistics, transport and reservations making the experience fitted to every user's need and motivation. Another relevant advancement under the umbrella of integrated digital ecosystems for the management of smart spaces is the work of Colace et al. [5]. The proposed context-aware framework relies on the five Slow Intelligence System principles (Enumeration, Propagation, Adaptation, Elimination and Concentration) for the tailoring of cultural heritage services in the form of behavioural intelligence. Retracing the emphasis on crowd-led mobile applications, we account for several other similar applications to the aforementioned that add salient features for developing a sustainable geoCA for ICH. For example, members of a local community can also be motivated to use such applications to upload data with authentic intangible cultural heritage information and pass it on to younger generations and people around the world [8]. The interpretation of active participation of the crowd as an enormous potential for gathering $\mathrm{ICH}$ data is what drives researchers to develop platforms such as Rock art CARE [34]. This type of geoCA is a cross platform mobile application for crowdsourcing information about UK rock art carvings, where the collated data is stored in a central location accessible by different stakeholders, in the attempt to preserve the national rock art through crowd participation. One of the main features of the application is the CARE Scorecard, based on a traffic light rating system for the semi-automated classification of rock art. This triangle approach assigns degrees of risk to rock art panels which aid the decision making about their care, thus automating the tailoring of the use of the application based on the needs of the project. Despite it not considering the need of the user for personalisation, the crowdsourcing application is an example of how similar systems could greatly benefit of additional features to further motivate its crowd of mappers, by, for instance, adding an element of item collection or competition between the users/players. The Amsterdam based MCHG ( Mobile Cultural Heritage Guide) by Van Aart et al. [36], offers another approach to location aware mobile devices for cultural heritage as it enriches the user experience by utilizing Linked Open Data sources for the recommendation of information. These and many other developments in geoCAs for $\mathrm{ICH}$ support the case for demonstrating the vast potential that can hatch from harnessing common technology by forging a link between the deployment of mobile devices and cultural heritage preservation.

\section{CRITICAL SUCCESS FACTORS SPECIFIC TO GEO-CROWDSOURCING}

Geo-crowdsourcing (GeoCS) has demonstrated itself to be a potential problem-solving tool for public management [18] as according to many scholars [31,37], taking advantage of citizens knowledge and engaging them could save public money and lead to more legitimate choices. As it is in the institutional and governmental interest to increase the engagement of its citizens, more smartphone platforms have been developed in recent years by means of integrating a territorial vision with the perception and input of the citizens and the crowd. This ambitious endeavour, however, does not always generate the expected results as the difficulties faced while attempting to significantly increase the value of the crowd's output are numerous. Of the identified critical success factors from the literature [18] these are considered the most relevant:

- Sufficient crowd participation

- Motive alignment of the crowd (e.g.: ways for kick-starting the crowd, crowd's motive alignment with long term objectives, etc.).

- Vision and strategy ( e.g.: vision in coherence with crowd's aspirations, goals and objectives of the stakeholders, etc.).

- Human capital (e.g.: skills of using a smartphone, skills, expertise and vision to put CS, usability, simplicity, etc.).

- Citizen-centric approach ( e.g.: technology adopted to citizens, operation systems compatibility, etc.).

- Linkage and trust (e.g.: support by stakeholders, marketing and PR plan, etc.).

- Security and privacy (e.g.: users anonymity, risk of liability, data privacy, etc.).

- Technical infrastructure (e.g.: spread of mobile phones, internet access, cost, etc.).

- Data quality (e.g.: data accuracy, data objectivity and credibility, localization accuracy, etc.).

- Management (e.g.: project manager, planning, setting up processes, etc.).

- Interaction orientation (e.g.: citizen-centricity, interaction configuration, etc.).

- Social networking (e.g.: communication and promotion plan, transparent and authentic communication, etc.).

- Customization on personalisation

- User added value

- Reward for participation (e.g.: monetary benefits, recognition).

- Financial capital (e.g.: monetary investments, associated costs).

- External Environment (e.g.: governance support, economic support, etc.).

In the following analysis the main focus is given to the point on Customization on personalisation [32], although many other factors, such as User added value, Interaction orientation, Reward for participation have been included in the discussion. Closely related to the research on potential motivators for contribution to 
volunteered geographic information is the work of Budhathoki and Haythornthwaite [4]. The authors provide a comprehensive list of different motivational factors found in the literature regarding domains for motivation: volunteerism, leisure, and the generation of online knowledge. These factors can also be assigned to two types of motivation theories:

A Intrinsic motivation, which comes from the individual themselves. It is defined as "doing something for its own sake".

B Extrinsic motivation, which is influenced by the outside. It refers to the "pursuit of an instrumental goal".

Both are very important as they are both positively associated with user participation [38]. For extrinsic motivation, one can think of gaining a positive reputation on the platform after a successful contribution or receiving a financial reward for contributing. These factors can provide a basis for investigating which motivations the participants of the city application can have. The intrinsic-extrinsic dualism has been recently criticised [29] of oversimplification. Multifaceted theories [28], in contrast, can help addressing the aspects of human motivation that the dualistic approach has failed at.

Budhathoki and Haythornthwaite [4] have also conducted a survey to try and understand which motivational factors were relevant for Open Street Map (OSM) volunteers. For their survey, they divided 444 OSM volunteers into two groups: serious mappers and casual mappers, based on how much and how often they contributed, as well as how long they had been contributing. The most essential motivational factors for both groups were two extrinsic factors, i.e. community and project goal, and two intrinsic factors, i.e. altruism, and unique ethos (meaning distinguishing ideals, values, sentiments, or guiding beliefs shared by volunteers). Other important factors were: fun, trust in the system, the freedom to provide information wherever they wanted and local knowledge (instrumentality and self-efficacy). Both groups also had some distinct results. Unique ethos was ranked higher by casual mappers, and learning by serious mappers. Understanding these motivational factors is important for providing strategies to turn casual mappers into serious ones, as serious mappers are more valuable for a participatory platform. Boosting the casual mapper's confidence and emphasizing the importance of local knowledge are two examples of strategies to turn casual mappers into serious ones. Tiwari et al. [33] have found that the most important factors for OSM and GISCorps (Geographic information system services) volunteers were: Altruism, Personal satisfaction, gaining new geo-spatial knowledge, strengthening of social relationships and fun. Their work is centered on identifying those motivational factors that facilitate the recruitment of users in VGI-systems. Volunteers were also questioned on which kind of incentives they thought would help increase their participation. Many volunteers were interested in additional geo-spatial training. Something that could be used to train volunteers is to use and provide templates, as this is described to be a motivational factor [20]. Using templates, volunteers can learn and train by filling in the templates until they do not need the templates anymore.

Composto et al. [6] found that volunteers wanted something back as an incentive for future contributions, such as feedback. Providing users with feedback regarding their contributions, can help assure users that their efforts are recognized and valued. This, in turn, can prompt users to reciprocate by more actively participating in crowdsourcing tasks and may make them feel loyal to the crowdsourcing project, resulting in even more participation [11]. Research has shown that crowdsourcing initiatives with more visible feedback had longer and more sustained participation [1,3]. The contribution of Composto et al. [6] extends to a better understanding of user engagement across time, as its results on users' behaviour explain how VGI geoCA was mostly used during working hours, with peak hours around 10 a.m. and 2 p.m. This finding justifies the assumption that people use crowdsourcing platforms such as the ones studied ("Signalez-nous" and "Urbangene"), at their workplaces, after drinking a coffee or having lunch. Considering this element of leisure and free-time that is attributed to the use of VGI goeCAs, the gamification of the user experience and the interface can, in theory, enhance the feeling of pleasure and enjoyment that the user gains from the contribution. Interestingly though, users actively participated in content creation mostly during evening hours [6], perhaps when less distracted. Not only the time of the day, but also the season has a clear impact on user's engagement with the application, as, for instance, the contribution frequency in winter was higher than during summer (however this result was determined primarily by the type of task). More interesting findings from the same research show that data quality increases if users need to authentify, since mandatory user authentication was found to be directly linked to better data quality. Lastly, platforms with tangible and instantaneous reward seem to perform better at retaining users since the direct and visible effects of contribution are stronger motivational factors than less detectable ones.

\section{USER MODELLING IN GEO-CROWDSOURCING APPLICATIONS}

In Location-Based Crowdsourcing ICH applications, all data capturing is actively done by the users in the form of images, georeferences, contextual attribution of information, data validation and data sharing. The type of selection of content that is generated by the collaboration of the crowds falls into the category of Active Crowdsourced Geographic Information (see Table 1). One of the most important part of the suggested user retention strategy is to look at how people can be attracted to contribute to the app using incentives, understand their motivations for contributing and respond to that, and how to retain these contributors. To help understand what the motivations for participating are and how they differ for the contributors, it is important to first find out which types of people participate in the crowdsourcing of geo-spatial data [30]. According to Heipke [20], Crowdsourcers can be categorized as follows:

- Map lovers and experts ("The groupies”) who are happy to provide accurate information in cases when maps are wrong or are missing information. These could be retired professional mappers; when they see something wrong on a map, they might be willing to let the authorities know.

- Casual mappers who can be part of a biking/hiking community and map whilst doing those activities. Casual mappers are most of the time only willing to spend a relatively low 
effort for mapping and would rather upload new data than looking for errors.

- Media mappers who respond to specific campaigns such as mapping parties and post-disaster events.

- Passive mappers who automatically provide information via their mobile phones often without even knowing it. This regards information such as where traffic jams occur.

- Open mappers who actively contribute to platforms such as OSM. This is by far the largest group, and their number is constantly growing. They are motivated by contributing and using good public data.

- Paid mappers who are driven by getting paid for doing an activity, e.g., Mechanical Turk from Amazon (a platform that pays users small amounts of money for small tasks).

For each category follows an overview of the motivators:

- For the map lovers and experts, but also for paid mappers, a common motivator for using geoCAS is the element of simplification that is provided to their lives, especially if these mappers are active people who are also leading map experts in organisations such as mountain rescue, civic protection, fire brigades etc. These users also tend to seek valuable and trustable information. Other motivational factors include: the reliability of the geoCAs system and the endorsement of mapping agencies with (financial) agreements

- Media mappers or one-off mappers, which are potentially large groups activated by media campaigns, are motivated by competitions, mapping parties, special rewards etc. The type of contribution expected from this group is limited in time. Over the long-term it would be advisable to migrate this user group to "casual mappers" or "groupies".

- Passive mappers are motivated by the passive and automated collection of information about positioning, time, and speed of the individuals. The passive mappers share similar attributes to the ones of the Open mappers.

- Open Mappers greatest motivator is the contribution to very valuable and large information to open source data sets or data systems. This means that they are motivated by contributing and making use of good public data. Enhancement and simplification of the Open Source Mapping Tools can greatly improve the participation of the Open Mappers groups.

- Casual mappers partly overlay with map lovers, but are distinguished by a lesser effort and therefore less valuable data production. Moderated forums and community platforms are necessary to attract these users group and turn them into critical mass.

- Paid Mappers, also known as "The Mechanical Turks" main motivator is financial reward.

Targeting the motivational strategy for each group of users, Nielsen [25]'s work on the 90-9-1 rule of participation inequality, can be considered as a simplified and unified list of guidelines, covering the majority of all groups of users' requirements for greater engagement. The key-points that should be taken into account when designing Open Contribution Systems are: a) make the act of contribution easy, without technical logistic, legal or intellectual barriers, b) make participation a side effect (principle of passive

\begin{tabular}{ll}
\hline Feature & Purpose \\
\hline Imaging & $\begin{array}{l}\text { Ask users to take and capture images of spe- } \\
\text { cific POIs } \\
\text { Leo-referencing }\end{array}$ \\
$\begin{array}{l}\text { Link these images to coordinates on the map } \\
\text { that will be used in the application }\end{array}$ \\
$\begin{array}{l}\text { Aalidation } \\
\text { Sharing }\end{array}$ & $\begin{array}{l}\text { Assess the quality of the contributions } \\
\text { Share contributions and other information }\end{array}$ \\
\hline
\end{tabular}

Table 1: List of recommended features for mobile applications developed for crowdsourced ICH.

mapping), c) prioritize on editing, discourage new the creation of disjointed content (by providing templates to ease the job to be done), d) reward the users, but don't over-reward active participants, otherwise they may end up dominating the whole project, and e) promote quality contributors, for example by reputation ranking. The last is particularly appealing for those geoCAS that have elements of competitive gaming, whilst generally, location-based platforms that incentivise users' ranking can be particularly appealing to some more active mappers (e.g. by encouraging feelings of pride in the neighbourhood/community).

Multiple strategies known to adaptive systems would be applicable also to crowdsourced ICH mobile applications. Strategies such as competition, comparison, cooperation, customization, reward, self-monitoring and feedback, suggestion, simulation, praise and personalisation are known to yield positive results [7].

The main challenge with geoCAs (or any mobile application that deals with a wide range of user groups) is the lack of personalisation. The approach of "one size-fits-all", i.e. applying the same methods to all users, is deemed to be detrimental and demotivating. With different users triggered and driven by different factors, a method that motivates one type of person may actually demotivate another one. Given that users' interests correlate to user involvement, a successful ICH geoCA should be good at providing an adapted solution to the functions of reward, suggestion, praise, customization, and more. Previous works by Fishbein et al. [12], Michie et al. [24], Fogg [13], propose distinct taxonomies of users' behaviours that we considered being valuable tools in determining and predicting behavioural traits of users. In Table 2, we present a summary of the determinants of behaviour adopted from the tutorial on personalisation for behaviour change by Masthoff and Vassileva [23].

Personalisation can help change user behaviour by, for example, increasing awareness towards the importance of $\mathrm{ICH}$, as well as towards the individual and collective contribution. The crowdworker or volunteer crowd participant should be personally motivated to make use of the application in the most proactive way, whilst being supported by an adaptive system that follows the transitional stages of the user's actions. One of the most popular theories, the Transtheoretical Model of Change (TTM) [27] - presents a three-stage system of user changes over a period of time (Pre-contemplation/ Contemplation, Preparation and Action/ Maintenance). This, or other theoretical models (e.g. The Model of Action Phases (MAP), 


\begin{tabular}{ll}
\hline Authors & Determinants \\
\hline Fishbein et al. [12] & $\begin{array}{l}\text { Self-standards; Skills; Self-efficacy; An- } \\
\text { ticipated outcomes/Attitude; Intention; } \\
\text { Environmental constraints; Norms; Emo- } \\
\text { tion. }\end{array}$ \\
Michie et al. [24] & Social/professional role and identity; \\
& Knowledge; Skills; Beliefs about capabili- \\
& ties; Beliefs about consequences; Motiva- \\
& tion and goals; Memory, attention and de- \\
& cision processes; Environmental context \\
& and resources; Social influences; Emo- \\
& tion; Behavioural regulation; Nature of \\
& behaviours. \\
& Ability; Motivation; Trigger.
\end{tabular}

Table 2: Determinants of user behavior according to three theoretical approaches to behavior change.

the I-Change Model (I-Change), The Health Action Process Approach (HAPA), The Precaution Adoption Process Model (PAPM) and more) can be instrumental in modelling an adequately responsive $\mathrm{ICH}$ application that adapts to the users' position (latitude of acceptance) over time.

\section{DESIGNING A FUTURE-PROOF ICH APP: THE CASE OF STORYBEE}

Based on the literature [19], we developed recommendations for our ICH app StoryBee, which captures ICH in cities through crowdsourcing. StoryBee is an Android application developed in the context of Utrecht University's Research IT innovation programme, project "Collaborative crowdsourcing tools for sustaining intangible urban heritage". The alpha version of the app was completed in January 2020 and is currently being tested. In Figure 2 we present an overview of the key design recommendations, which, according to the literature, are essential for the design of a successful mobile $\mathrm{ICH}$ application, and which drive the design of StoryBee, namely: imaging, geo-referencing, contextualization and sharing. The application is designed to function as geoCA for $\mathrm{ICH}$ by adopting a number of features that we have so far discussed in the literature.

Great emphasis has been put on the user experience as interaction created together with others. Unlike the more established route of mobile application conceived around the individualistic bias of usability as enjoyable experience of the single user, StoryBee was designed as a tool for the enjoyment of the co-experience. The tool allows people to communicate emotions with each other via mobile multimedia technology. It offers a list of stories crafted by its contributors and filtered by its moderators, enriched with images and metadata provided by the users themselves. The user is allowed to browse other user's stories, search for the ones in the vicinity (geo-locating them with GPS technology) and even keep a log of published and unpublished stories. The collectively crafted stories are then tightly linked with the places of interest, from which they originated, and are presented in the form of cards. For each card e.g. Vredenburg, Plaza de Espana etc., the interface offers an intuitive overview of the amount of stories written in that area by all contributors, the last time the user visited the place of interest plus an iconic image of the area for easy identification. StoryBee offers its users to discover new places by asking questions such as: "How many meters do you want to walk?", "How many places do you want to visit?" and "What do you find interesting?". The information collected is used to enlarge the user database with tags that aid the system to recommend places and stories that are most suitable to the reader. The same parameters are used by the collaborator to create routes around cultural sites.

The framework's ability to engage and motivate the crowd is primarily, but not only, based on the gamefication experience of visiting cultural sites, provided by the option to collect different types of trophies. Additional features of the StoryBee application include: the option to select stories from a particular area and to download them in offline mode (the interface displays the total amount of stories and the exact amount of memory storage required for the download), the option to read other people's stories by choosing the keywords/tags, the option to edit, permanently delete and un-publish the authored story before it is assessed by the moderators, to unlock stories based on geographic proximity and much more. Table 3 illustrates the key features underpinning the design of StoryBee alongside their type of motivation and personalisation factors.

The StoryBee features have been chosen based on three main groups of crowdsourcers:

- Casual StoryBee user: For visitors and inhabitants who want to discover the stories behind locations both popular and hidden.

- Cultural StoryBee expert: For cultural experts who want as many people as possible to discover the area and collect intangible cultural heritage.

- StoryBee Administrator; For administrators who want to moderate and maintain all user content.

The application is designed to work on multiple platforms (web, mobile and tablet) in consideration to the different user needs (i.e. to assist the work of moderators, the desktop version was envisaged). From the viewpoint of motivational triggers, stories have been made visible only when the user moves within a certain radius of the location, this is done to encourage the StoryBee mappers to explore and physically visit the points of interest. The feature of story creation by all users was conceived for the collection of as many authentic stories as possible and the encouragement of user participation.

\section{CONCLUSION}

The decision to opt for a digital medium when preserving ICH can significantly help the expansion of participation and outreach to a number of users, whilst increasing transparency. More so, the digitisation and popularisation of ICH through mobile technology can represent a novel shift in information flow. In general, all results that have been derived from the literature, and presented in this paper, can be used for the design of mobile ICH applications that leverage user motivation. These features make sure people have the chance to capture and gather their own intangible information and at the same time are motivated to use them. it is therefore clear that most of the features try to reduce the effort people have to make 


\begin{tabular}{|c|c|c|}
\hline StoryBee key Feature & Purpose & User Primary Motivators \\
\hline Map & Contains all user stories about the map & Gaining new geo-spatial knowledge \\
\hline Read a story & $\begin{array}{l}\text { Contains all user stories pertaining to the displaying } \\
\text { of stories }\end{array}$ & $\begin{array}{l}\text { Strengthening of social relationships; Personal satis- } \\
\text { faction }\end{array}$ \\
\hline Story feedback & Contains all user stories about user feedback & $\begin{array}{l}\text { Learning; Self-expression; Self-image; Instrumentality; } \\
\text { Self-efficacy; Freedom to express; Altruism; Career; } \\
\text { Social relations; Reputation; Reciprocity }\end{array}$ \\
\hline Manage stories & $\begin{array}{l}\text { Contains every user story which has something to do } \\
\text { with creating, editing and deleting stories }\end{array}$ & $\begin{array}{l}\text { Unique Ethos; Learning opportunity; Personal enrich- } \\
\text { ment; Self-expression; Self-image; Hedonistic gains; } \\
\text { Recreation; Meeting own need; Freedom to express; } \\
\text { System trust }\end{array}$ \\
\hline Accounts & $\begin{array}{l}\text { Consists of all stories related to accounts and their } \\
\text { rights. }\end{array}$ & $\begin{array}{l}\text { Networking; System trust; Reciprocity; Reputation; } \\
\text { Community engagement; Learning Opportunity }\end{array}$ \\
\hline Moderating & Contains all user stories about the admin account & $\begin{array}{l}\text { Reputation; Monetary return (if any); Instrumentality; } \\
\text { Recreation; Altruism; Personal enrichment }\end{array}$ \\
\hline
\end{tabular}

Table 3: Six significant features of the StoryBee program and relative motivational factors.

to actually use the app and contribute content. Templates, smart walks, making it a side effect, and familiarity and proximity all reduce the amount of time, thoughts and effort the user has to make in order to add content or use the app. Using gamification has also been proven beneficial. On almost every screen of StoryBee some sort of game-element can be seen. Points, leader boards, reputation, and badges make sure the app is fun to use and thus prolonging the retention and continuation of users. In this paper we present an overview of the technologies, crowdsourcing methods and systems, motivational factors, incentives and methods, to safeguard $\mathrm{ICH}$ and make more certain recommendations that can be used in the production of mobile $\mathrm{ICH}$ applications. Those recommendations, visualised in the mock-ups of StoryBee can provide development teams with good ideas of what a cultural geo-located application could look like, how its features could be implemented and how certain of its features could work. Going mobile would promote the continuous evolution and expansion of $\mathrm{ICH}$, provided that regulators maintain a distinct role and take on a greater responsibility in reserving this particular facet of our cultural heritage.

\section{ACKNOWLEDGEMENTS}

This research has been supported by Utrecht University's "Innovation fund for IT in research", project title "Collaborative crowdsourcing tools for sustaining intangible cultural heritage". We acknowledge the contribution to the paper by the work of Bas Hannewijk entitled 'Capturing the Intangible. Creating a city application with crowdsourced content for preserving intangible cultural heritage.'

\section{REFERENCES}

[1] Simon à Campo, Vasssilis-Javed Khan, Konstantinos Papangelis, and Panos Markopoulos. 2019. Community heuristics for user interface evaluation of crowdsourcing platforms. Future Generation Computer Systems 95 (June 2019), 775-789. https://doi.org/10.1016/j.future.2018.02.028

[2] Flora Amato, Angelo Chianese, Vincenzo Moscato, Antonio Picariello, and Giancarlo Sperli. 2012. SNOPS: a smart environment for cultural heritage applications. In Proceedings of the twelfth international workshop on Web information and data management. 49-56.

[3] Jailson Brito, Vaninha Vieira, and Adolfo Duran. 2015. Towards a framework for gamification design on crowdsourcing systems: the GAME approach. In 2015 for gamification design on crowdsourcing systems: the GAME approach. In 2015
$12 t h$ International Conference on Information Technology-New Generations. IEEE, 445-450.
[4] Nama R Budhathoki and Caroline Haythornthwaite. 2013. Motivation for open collaboration: Crowd and community models and the case of OpenStreetMap. American Behavioral Scientist 57, 5 (2013), 548-575.

[5] Francesco Colace, Massimo De Santo, Luca Greco, Saverio Lemma, Marco Lombardi, Vincenzo Moscato, and Antonio Picariello. 2014. A context-aware framework for cultural heritage applications. In 2014 Tenth International Conference on Signal-Image Technology and Internet-Based Systems. IEEE, 469-476.

[6] Sarah Composto, Jens Ingensand, Marion Nappez, Olivier Ertz, Daniel Rappo, Rémi Bovard, Ivo Widmer, and Stéphane Joost. 2016. How to recruit and motivate users to utilize VGI-systems. In 19th AGILE Conference on Geographic Information Science, Helsinki, Finland.

[7] Sunny Consolvo, David W McDonald, and James A Landay. 2009. Theory-driven design strategies for technologies that support behavior change in everyday life. In Proceedings of the SIGCHI conference on human factors in computing systems. 405-414.

[8] Hari Krishna Dhonju, Wen Xiao, Bandana Shakya, Jon P Mills, and Vasilis Sarhosis. 2017. Documentation of heritage structures through geo-crowdsourcing and webmapping. In The International Archives of the Photogrammetry, Remote Sensing and Spatial Information Sciences, Vol. 42. Copernicus Publications, 17-21.

[9] Michael Di Giovine. 2011. The Heritage Reader. Curator: The Museum fournal 54, 3 (2011), 363-369.

[10] Kosmas Dimitropoulos, Sotiris Manitsaris, Filareti Tsalakanidou, Spiros Nikolopoulos, Bruce Denby, Samer Al Kork, Lise Crevier-Buchman, Claire PillotLoiseau, Martine Adda-Decker, Stephane Dupont, et al. 2014. Capturing the intangible an introduction to the i-Treasures project. In 2014 International conference on computer vision theory and applications (VISAPP), Vol. 2. IEEE, 773-781.

[11] Yuanyue Feng, Hua Jonathan Ye, Ying Yu, Congcong Yang, and Tingru Cui. 2018. Gamification artifacts and crowdsourcing participation: Examining the mediating role of intrinsic motivations. Computers in Human Behavior 81 (2018), 124-136.

[12] Martin Fishbein, Harry C Triandis, Frederick H Kanfer, Marshall Becker, Susan E Middlestadt, Anita Eichler, et al. 2001. Factors influencing behavior and behavior change. Handbook of health psychology 3 (2001), 17.

[13] Brian J Fogg. 2009. A behavior model for persuasive design. In Proceedings of the 4th international Conference on Persuasive Technology. 1-7.

[14] Chiara Garau. 2014. From territory to smartphone: Smart fruition of cultural heritage for dynamic tourism development. Planning Practice and Research 29, 3 (2014), 238-255.

[15] Chiara Garau and Emiliano Ilardi. 2014. The "Non-Places" meet the "Places:" Virtual tours on smartphones for the enhancement of cultural heritage. Fournal of Urban Technology 21, 1 (2014), 79-91.

[16] Michael F Goodchild. 2007. Citizens as sensors: the world of volunteered geography. Geofournal 69, 4 (2007), 211-221.

[17] Rebecca Goolsby. 2010. Social media as crisis platform: The future of community maps/crisis maps. ACM Transactions on Intelligent Systems and Technology (TIST) $1,1(2010), 1-11$

[18] Barbora Haltofová. 2019. Critical success factors of geocrowdsourcing use in e-government: a case study from the Czech Republic. Urban Research \& Practice (2019), 1-18.

[19] Bas Hannewijk, Federica Lucia Vinella, Vassilis-Javed Khan, Ioanna Lykourentzou, Konstantinos Papangelis, and Judith Masthoff. 2020. Capturing the City's Heritage 
On-the-Go: Design Requirements for Mobile Crowdsourced Cultural Heritage. Sustainability 12, 6 (2020), 2429.

[20] Christian Heipke. 2010. Crowdsourcing geospatial data. ISPRS fournal of Photogrammetry and Remote Sensing 65, 6 (2010), 550-557.

[21] Sirkka L Jarvenpaa and Karl R Lang. 2005. Managing the paradoxes of mobile technology. Information systems management 22, 4 (2005), 7-23.

[22] Jesper Kjeldskov and Connor Graham. 2003. A review of mobile HCI research methods. In International Conference on Mobile Human-Computer Interaction. Springer, 317-335.

[23] Judith Masthoff and Julita Vassileva. 2015. Tutorial on personalization for behaviour change. In Proceedings of the 20th International Conference on Intelligent User Interfaces. 439-442.

[24] S1 Michie, Marie Johnston, Charles Abraham, R Lawton, D Parker, and A Walker 2005. Making psychological theory useful for implementing evidence based practice: a consensus approach. BMF Quality \& Safety 14, 1 (2005), 26-33.

[25] Jakob Nielsen. 2006. The 90-9-1 rule for participation inequality in social media and online communities.

[26] Konstantinos Papangelis, Alan Chamberlain, and Hai-Ning Liang. 2016. New directions for preserving intangible cultural heritage through the use of mobile technologies. In Proceedings of the 18th International Conference on HumanComputer Interaction with Mobile Devices and Services Adjunct - MobileHCI '16. ACM Press. https://doi.org/10.1145/2957265.2962643

[27] James O Prochaska, Colleen A Redding, Kerry E Evers, et al. 2015. The transtheoretical model and stages of change. Health behavior: Theory, research, and practice (2015), 125-148.

[28] Steven Reiss. 2004. Multifaceted nature of intrinsic motivation: The theory of 16 basic desires. Review of general psychology 8, 3 (2004), 179-193.

[29] Steven Reiss. 2012. Intrinsic and extrinsic motivation. Teaching of Psychology 39, $2(2012), 152-156$
[30] Linda See, Giles Foody, Steffen Fritz, Peter Mooney, Ana-Maria Olteanu-Raimond, Cidalia Maria Parreira da Costa Fonte, Vyron Antoniou, and Cidália Costa Fonte. 2017. Mapping and the Citizen Sensor. (2017).

[31] Ethan Seltzer and Dillon Mahmoudi. 2013. Citizen participation, open innovation, and crowdsourcing: Challenges and opportunities for planning. Fournal of Planning Literature 28, 1 (2013), 3-18.

[32] Jayakumar Sowmya and Hussain Shafiq Pyarali. 2014. The Effective Use of Crowdsourcing in E-Governance. Nanyang Technological University, Singapore. Accessed Fanuary (2014).

[33] Rupa Tiwari, Ankita Agrawal, and Shashi Shekhar. 2010. Contributions of volunteered geographic world: Motivation behind contribution. In Workshop on Role of Volunteered Geographic Information in Advancing Science, International Conference on Geographic Information Science.

[34] Mark Turner, Stephen Dowsland, Aron Mazel, and Myra Giesen. 2018. Rock art CARE: A cross-platform mobile application for crowdsourcing heritage conservation data for the safeguarding of open-air rock art. fournal of Cultural Heritage Management and Sustainable Development (2018).

[35] Scientific United Nations Educational and Cultural Organization (UNESCO). 2003. Convention for the safeguarding of the intangible cultural heritage.

[36] Chris Van Aart, Bob Wielinga, and Willem Robert Van Hage. 2010. Mobile cultural heritage guide: location-aware semantic search. In International Conference on Knowledge Engineering and Knowledge Management. Springer, 257-271.

[37] Roumen Vragov and Nanda Kumar. 2013. The impact of information and communication technologies on the costs of democracy. Electronic Commerce Research and Applications 12, 6 (2013), 440-448.

[38] Zhiyuan Zeng, Jian Tang, and Tianmei Wang. 2017. Motivation mechanism of gamification in crowdsourcing projects. International fournal of Crowd Science (2017) 